\title{
Investigation of the strain induced effect on a linear shape fiber Bragg grating embedded in a composite material
}

\author{
M. Szeląg*, P. Lesiak, D. Budaszewski, M. Chychłowski, and T.R. Woliński \\ Faculty of Physics, Warsaw University of Technology, Koszykowa 75, 00-662 Warszawa,
}

Received June 22, 2016; accepted July 21, 2016; published September 30, 2016

\begin{abstract}
In this work experimental results are presented of strain induced effects on a linear shape fiber Bragg grating embedded in a composite material. Mechanical analysis of the composite material has been numerically performed by using commercially available software Ansys. Advanced Bragg gratings make it possible to simplify detection systems, calibration process of fiber optic sensors and quasi - spot metering.
\end{abstract}

Fiber Bragg grating sensors (FBGs) are optical sensors recorded within the core of a standard single-mode optical fiber. FBGs can be used for strain and temperature and other measurements such as pressure, acceleration and displacement [1-3]. Additionally, they can be easily suited to composite materials made of reinforced glass and carbon fiber because of their similar mechanical properties [4-15].

Changes in strain affect both the effective refractive index $n_{\text {eff }}$ and the grating period $\Lambda$ of FBG, which results in a shift in the reflected wavelength:

$$
\Delta \lambda_{B}=2\left(\Lambda \frac{\partial n_{e f f}}{\partial \varepsilon}+n_{e f f} \frac{\partial \Lambda}{\partial \varepsilon}\right) \Delta \varepsilon,
$$

where $\lambda_{B}$ is the Bragg wavelength and $\Delta \varepsilon$ is the relative strain change of FBG defined as:

$$
\Delta \varepsilon=\frac{\Delta l}{l},
$$

where $\Delta l$ is the length change of FBG and $l$ is the initial length of FBG.

In order to determine the level of degradation of a composite material, a novel generation of FBGs has been used.

A linear shape FBG (LSFBG) is a special type of chirped fiber Bragg grating, characterized by linear variation in the grating period. In our studies, we used an LSFBG manufactured by $\mathrm{O} / \mathrm{E}$ Land Inc. which was inscribed in SMF-28 optical fiber of a length of $15 \mathrm{~mm}$, for the central wavelength at $1300 \mathrm{~nm}$. The LSFBG was embedded between the $4^{\text {th }}$ and $5^{\text {th }}$ ply of a composite structure consisting of six carbon fiber layers. These layers are stacked in order $0^{\circ} / 0^{\circ} / 0^{\circ} / 0^{\circ} / 0^{\circ} / 0^{\circ}$. The sample was 300 - mm-long, 40-mm-wide and 0.9-mm-thick. The sensing part of the LSFBG was located $150 \mathrm{~mm}$ from the left side of the composite plate. A superluminescent diode (SLD) operating at the central wavelength of $1300 \mathrm{~nm}$ was used as an input light source. The Bragg wavelength displacement of the LSFBG sensor was measured by using an optical spectrum analyzer (ANDO AQ 6315E) and a simple power meter KI9600A (Fig. 1).

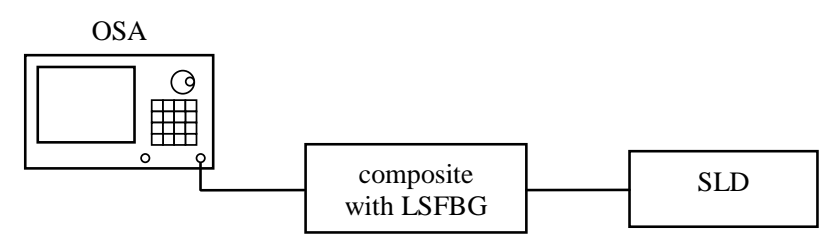

Fig. 1. Schematic diagram of the measurement technique.

A typical transmitted spectrum of the LSFBG is presented in Fig. 2. The optimal power of SLD is $2 \mathrm{~mW}$.

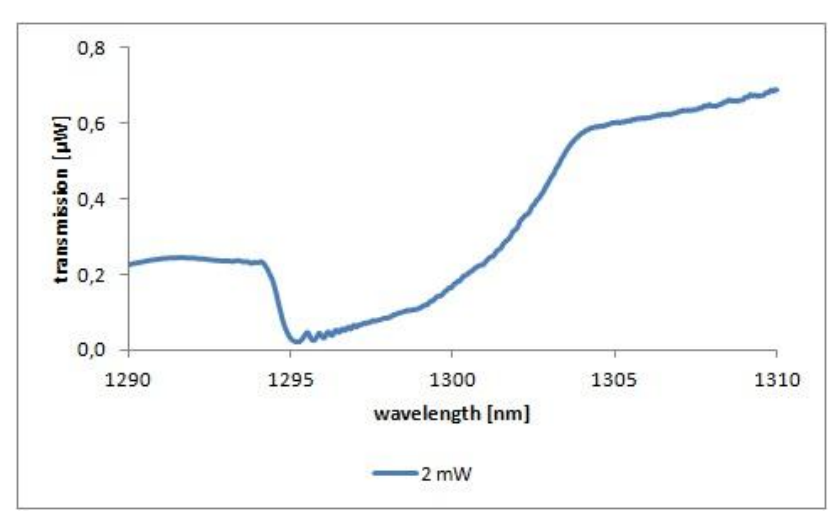

Fig. 2. Transmitted spectra of LSFBG for different power of an optical light source in linear scale.

The material used to fabricate a composite structure is called prepreg. These preimpregnated semi-finished products offer maximum material performance, especially for complex components. The mechanical parameters of the carbon fiber composite material used in our study are shown in Tab. 1,

\footnotetext{
*E-mail: matsze@if.pw.edu.pl
} 
Tab. 1. Mechanical properties of a carbon fiber composite material

\begin{tabular}{cccccc}
\hline \hline $\begin{array}{c}\text { Total thickness } \\
{[\mathrm{mm}]}\end{array}$ & $\begin{array}{c}\mathrm{E}_{\mathrm{X}} \\
{[\mathrm{GPa}]}\end{array}$ & $\begin{array}{c}\mathrm{E}_{\mathrm{Y}} \\
{[\mathrm{GPa}]}\end{array}$ & $\begin{array}{c}\mathrm{G}_{\mathrm{XY}} \\
{[\mathrm{GPa}]}\end{array}$ & $\begin{array}{c}\mathrm{G}_{\mathrm{YZ}} \\
{[\mathrm{GPa}]}\end{array}$ & $v_{\mathrm{XY}}$ \\
\hline 0.9 & 96.3 & 8.5 & 6.0 & 1.3 & 0.295 \\
\hline \hline
\end{tabular}

where E is Young's modulus, $\mathrm{G}$ is the shear modulus, $v$ is Poisson's ratio.

In this paper one-dimensional model is considered of the composite structure fixed at both ends and with a centrally applied load (Fig. 3).

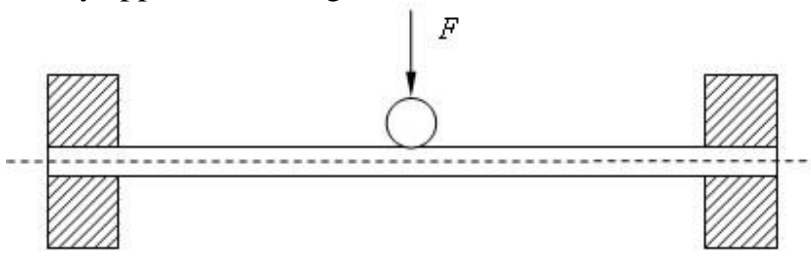

Fig. 3. Mechanical model of a composite structure fixed at both ends and with a centrally applied load.

The dependence of strain on deflection is shown in Tab. 2 . To determine the distribution of strain in the composite structure, a finite element method type SHELL281 available in ANSYS software was used. To determine the value of strain affecting the LSFBG implemented in the composite material, the von Mises yield criterion was used. We have investigated the Gaussian approach of strain distribution that can be applied to a fiber Bragg grating embedded in a composite material:

$$
\varepsilon(z)=\varepsilon_{0} \cdot \exp \left\{-\ln 2 \cdot\left[\frac{2 \cdot\left(z-\frac{L}{2}\right)}{w \cdot L}\right]^{2}\right\},
$$

where $\varepsilon_{\mathrm{o}}$ is the peak strain value and $w$ is the normalized value of FWHM.

\begin{tabular}{cccccc}
\multicolumn{5}{c}{ Tab. 2. Applying strain to LSFBG } \\
\hline $\begin{array}{c}\text { deflection } \\
\mathrm{U}_{\mathrm{z}}\end{array}$ & $2 \mathrm{~mm}$ & $4 \mathrm{~mm}$ & $6 \mathrm{~mm}$ & $8 \mathrm{~mm}$ & $10 \mathrm{~mm}$ \\
\hline $\begin{array}{c}\text { strain } \\
{[\mu \varepsilon]}\end{array}$ & 101 & 202 & 304 & 405 & 506 \\
\hline \hline
\end{tabular}

In typical FBGs, applied strain changes the Bragg wavelength. A similar situation for LSFBG has been observed where tensile stress shifts the Bragg wavelength toward longer values (Fig. 4.) Figure 5 shows how the Bragg wavelength shift depends on strain induced in a compressive and tensile layer. The obtained values allow us to calculate strain sensitivities for tensile $\left(\mathrm{K}_{\varepsilon+}\right)$ and compressive $\left(\mathrm{K}_{\varepsilon}\right)$ layers (Tab. 3). These values are a little lower than the $K_{\varepsilon}=1.0 \mathrm{pm} / \mu \varepsilon$ predicted for a bare SMF-28 fiber before lamination.

Tab. 3. Strain sensitivity in tensile and compressive layer measured by

\begin{tabular}{ccc}
\multicolumn{3}{c}{ using OSA } \\
\hline \hline $\begin{array}{c}\mathrm{K}_{\varepsilon+} \\
{[\mathrm{pm} / \mu \varepsilon]}\end{array}$ & $\begin{array}{c}\mathrm{K}_{\varepsilon-} \\
{[\mathrm{pm} / \mu \varepsilon]}\end{array}$ & $\begin{array}{c}\text { applying } \\
\text { force at }\end{array}$ \\
\hline 9.1 & -8.5 & $15 \mathrm{~cm}$ \\
\hline \hline
\end{tabular}

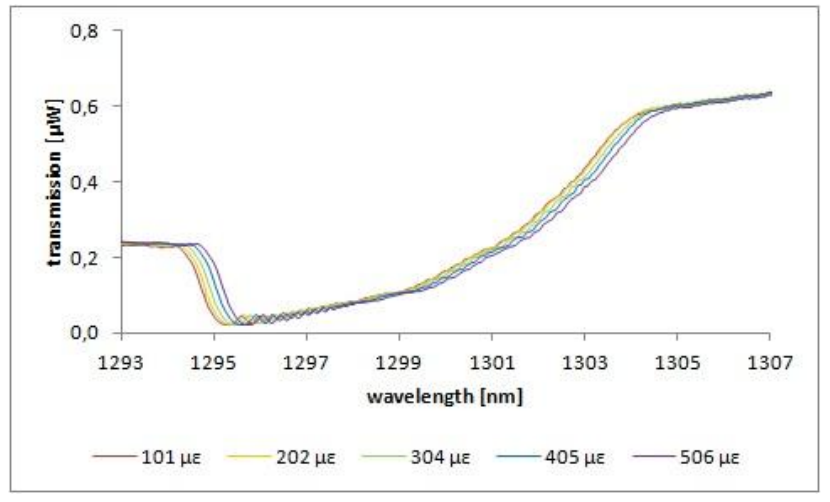

Fig. 4. Transmitted spectra of LSFBG without $(0 \mu \varepsilon)$ and under strain $(101 \mu \varepsilon, 202 \mu \varepsilon)$.

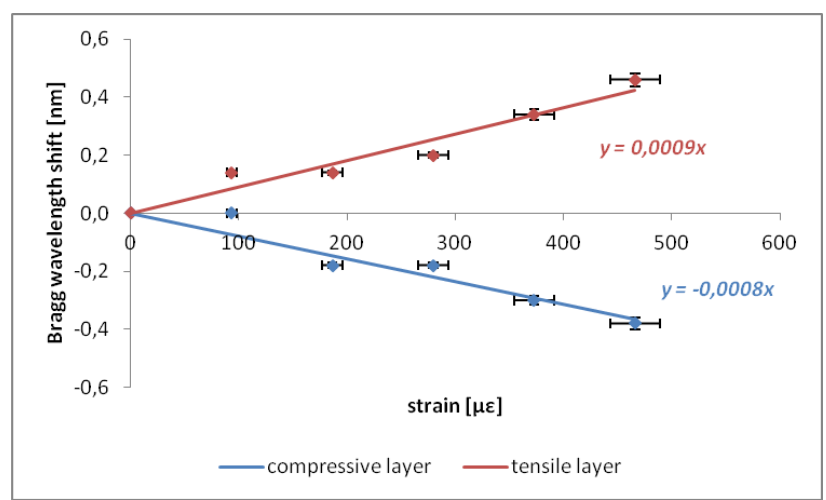

Fig. 5. Bragg wavelength shift as a function of strain.

However, the use of LSFBG implemented in a composite material has a very important advantage. The linear characteristics of the investigated FBGs allow us to establish the relationship between the Bragg wavelength shift and the power of a transmission spectrum for the chosen wavelength, so the strain sensitivity of LSFBG can be expressed either by $\mathrm{pm} / \mu \varepsilon$ or $\mathrm{nW} / \mu \varepsilon$. Figure 6 presents the experimental results obtained by using an optical power meter KI9600A and a laser diode working at $1300 \mathrm{~nm}$. As it was shown in Fig. 4, the LSFBG placed in a tensile layer exhibits a decrease of light intensity for $1300 \mathrm{~nm}$. That is why strain sensitivity for the tensile layer is negative and for the compressive layer is positive (Tab. 4.). This confirms our early experimental results [16].

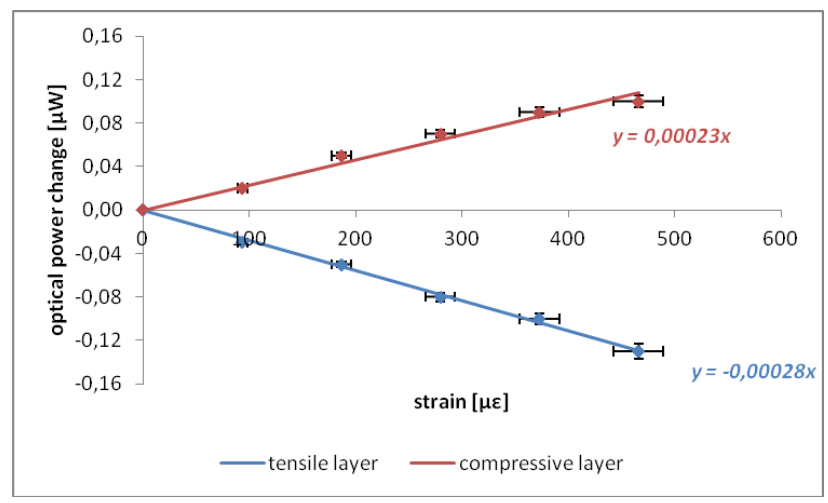

Fig. 6. Optical power change as a function of strain. 
Tab. 4. Strain sensitivity in tensile and compressive layer measured by using power meter KI9600A

\begin{tabular}{ccc}
\hline $\begin{array}{c}\mathrm{K}_{\varepsilon+} \\
{[\mathrm{nW} / \mu \varepsilon]}\end{array}$ & $\begin{array}{c}\mathrm{K}_{\varepsilon_{-}} \\
{[\mathrm{nW} / \mu \varepsilon]}\end{array}$ & $\begin{array}{c}\text { applying } \\
\text { force at }\end{array}$ \\
\hline-0.28 & 0.23 & $15 \mathrm{~cm}$ \\
\hline \hline
\end{tabular}

The measurement results presented in this paper show that stress-induced effects in the fiber optic sensors correspond to stress distribution in the deformed composite material. LSFBG provides a significant advantage for the calibration process of fiber optic sensors due to its linear response to strain. Another advantage is the possibility to simplify detection systems and quasi - spot metering. The experimental results presented in this work make it possible to create a fiber optic sensor, which can be dedicated to composite structures.

This work was supported by the Faculty of Physics Dean's grant and the National Centre for Research and Development under the grant PBS1/B5/20/2012.

\section{References}

[1] P. Kisała, Przegląd Elektrotechniczny 11a, 343 (2012).

[2] X. Wen, D. Zhang, Y. Qian, J. Li, N. Fei, Sensors Actuat. A: Phys. 174, 91 (2012).

[3] H. Peng, Y. Su, Z. Ye, B. Zhou, Opt. Fiber Technol. 18(6), 485 (2012).

[4] G. Luyckx, E. Voet, N. Lammens, J. Degrieck, Sensors 11, 384 (2011).

[5] S. Yashiro, N. Takeda, T. Okabe, H. Sekine, Composites Science Technol. 65, 659 (2005).

[6] Y. Zhan, L. Li, F. Yang, K. Gu, H. Wu, M. Yu, Opto-Electron. Rev. 21(3), 283 (2013).

[7] Y. Okabe, R. Tsuji, N. Takeda, Composites: Part A 35, 59 (2004).

[8] S. Yashiro, T. Okabe, N. Toyama, N. Takeda, Intern. J. Solids Structur. 44, 603 (2007).

[9] C. Fernandez-Valdivielso, I.R. Matoas, F.J. Arregui, Sensors Actuat. A: Phys. 101, 107 (2002).

[10] A. Makovec, G. Berruti, M. Consales, M. Giordano, P. Petagna, S. Buontempo, G. Breglio, Z. Szillasi, N. Beni, A. Cusano, J. Instrumentation 9(3), C03040 (2014).

[11] P. Kisała, Przegląd Elektrotechniczny, NR 1a, R. 89, 29 (2013).

[12] A. Papantoniou, G. Rigas, N.D. Alexopoulos, Composite Structur. 93, 2163 (2011).

[13] Y. Okabe, R. Tsuji, N. Takeda, Composites: Part A 35, 59 (2004).

[14] P.Lesiak, M.Szeląg, D.Budaszewski, R.Plaga, K.Mileńko, G.Rajan, Y.Semenova, G.Farrell, A.Boczkowska, A.Domański, T.Woliński, „Influence of lamination process on optical fiber sensors embedded in composite material", Measurement, Vol. 45 , Issue 9, November 2012, Pages 2275-2280.

[15] P. Lesiak, M. Szeląg, K. Mileńko, T. Woliński, A. Domański, K. Jędrzejewski, A. Boczkowska, Acta Phys. Polonica A 120, 698 (2011).

[16] A.W. Domański, P. Lesiak, K. Milenko, A. Boczkowska, D. Budaszewski, S. Ertman, T.R. Woliński, Photon. Lett. Poland 1(3), 121 (2009). 